\title{
A Comissão da Verdade no Brasil: a luta pela memória em uma democracia fragilizada
}

The Truth Commission in Brazil: The Struggle for Memory in a Fragile Democracy

La Commission de la vérité au Brésil: la lutte pour la mémoire dans une démocratie fragile

Celia Regina do Nascimento de Paula e Fernando Antonio da Costa Vieira

\section{OpenEdition}

\section{Journals}

Edição electrónica

URL: http://journals.openedition.org/rccs/10371

DOI: $10.4000 /$ rccs. 10371

ISSN: 2182-7435

\section{Editora}

Centro de Estudos Sociais da Universidade de Coimbra

\section{Edição impressa}

Data de publição: 1 maio 2020

Paginação: 123-146

ISSN: 0254-1106

\section{Refêrencia eletrónica}

Celia Regina do Nascimento de Paula e Fernando Antonio da Costa Vieira, «A Comissão da Verdade no Brasil: a luta pela memória em uma democracia fragilizada », Revista Crítica de Ciências Sociais [Online], 121 | 2020, posto online no dia 15 abril 2020, consultado o 17 abril 2020. URL : http:// journals.openedition.org/rccs/10371 ; DOI : https://doi.org/10.4000/rccs.10371 


\section{CELIA REGINA DO NASCIMENTO DE PAULA, FERNANDO ANTONIO DA COSTA VIEIRA}

\section{A Comissão da Verdade no Brasil: a luta pela memória em uma democracia fragilizada}

Instituída no Brasil em 2012, a Comissão Nacional da Verdade (CNV) apresentou relatório das suas ações em 2014. Ao torná-lo público, a CNV, além de citar nominalmente os agentes do Estado que violaram direitos humanos, apresentou relatos sobre as mortes de 434 pessoas, vítimas de arbitrariedades, descrições sobre técnicas de tortura, execuções, detenções ilegais, desaparecimentos forçados e ocultações de cadáveres. O presente trabalho visa debater a ação da CNV dentro dos limites que Ihe foram impostos - o de considerar a Lei de Anistia de 1979 - e o eixo da luta pelo resgate da memória negada aos desaparecidos políticos. A análise de documentos produzidos pela CNV e as reportagens produzidas pela mídia serão o material utilizado para a produção deste artigo.

Palavras-chave: anistia; Brasil; ditadura; memória; presos políticos.

\section{O contexto histórico entre o golpe de 1964 e a decretação do Ato Institucional n. $^{\circ} 5$}

Desde o início do novo regime instituído no Brasil após o golpe de Estado iniciado em 31 de março de 1964 e consolidado no dia seguinte, foram adotadas medidas repressivas ante a oposição, nomeadamente contra os quadros do governo de João Goulart (1961-1964) e lideranças reconhecidas da esquerda. Golpe que, para René Armand Dreifuss, expressou

as contradições estruturais do Estado capitalista em sua forma populista pela vanguarda civil e militar do bloco empresarial modernizante-conservador. Isso significava que as ideologias empresariais e a doutrinação política convergiam para o ponto no qual o entendimento das necessidades de mudança seria traduzido em ação política, enquanto que as forças políticas tradicionais tentavam ainda sobrepor-se aos conflitos básicos, mantendo-os dentro de certos limites históricos que haviam se esgotado. (Dreifuss, 1987: 145) 
Em 9 de abril de 1964, o Comando Supremo da Revolução, composto pelo general Costa e Silva, pelo almirante Rademaker Grünewald e pelo tenente-brigadeiro Francisco de Assis, promulgou o Ato Institucional n. ${ }^{\circ}$ 1(AI-1). Por este ato, eram cassados os direitos políticos de 100 lideranças políticas, entre elas, o presidente deposto João Goulart, o ex-governador de Pernambuco Miguel Arraes, o líder do Partido Comunista Brasileiro (PCB) Luiz Carlos Prestes e o deputado federal Leonel Brizola.

O AI-1 iniciou uma política de limpeza que buscava inviabilizar as ações da oposição ao novo governo militar no país. Esse processo contou com o apoio dos principais órgãos de comunicação do Brasil. Em 2 de abril de 1964, o jornal O Globo denunciou o manifesto de fundação do Comando dos Trabalhadores Intelectuais (CTI), apresentado à sociedade em outubro de 1963. Ao republicá-lo, o jornal assinalava que o CTI havia trabalhado "ativamente pela implantação de um regime comunista no Brasil" (O Globo, 2 de abril de 1964, p. 14). E avançava afirmando: "Republicando-o agora, chamamos a atenção do alto-comando Militar para os nomes que o assinaram" (ibidem). Assumindo o papel de denunciantes, jornais - como O Globo -, apostavam na implementação de forte repressão aos adversários do vitorioso movimento militar.

Após ser indicado candidato para a presidência da República pelo Comando Militar, em 11 de abril de 1964, o marechal Humberto Castelo Branco foi eleito por um Congresso Nacional em que a oposição havia sido expulsa e os poucos órgãos de imprensa opositores censurados e sob vigilância. É importante lembrar que

o novo chefe de governo passou a ter o poder de cassar mandatos de autoridades eleitas, inclusive os parlamentares, além de suspender os direitos políticos de qualquer cidadão por 10 anos, e permitir ao Poder Executivo legislar por decretos-leis, independente da aprovação do legislativo. (Freixo et al., 2008: 16)

Ficava claro a concentração de poder discricionário junto ao presidente da República, capacitando-o a impor a política que fosse, sem a necessidade de negociar e dialogar com os parlamentares. Entretanto, o emprego da violência do Estado ainda se encontrava em fase inicial e, mesmo quando preso, o aparato jurídico podia intervir e libertar o opositor, na medida em que ainda vigoravam mecanismos legais que garantiam as liberdades individuais. Tudo mudaria com o recrudescimento da ditadura após $1968 .{ }^{1}$

\footnotetext{
${ }^{1}$ A definição de ditadura abordada será a de "regimes antidemocráticos ou não democráticos modernos". Portanto, uma "ditadura se distingue em contraposição, por uma concentração de poder e pela transmissão da autoridade política de cima para baixo” (Bobbio et al., 1995: 370).
} 
Em 9 de maio de 1964, Carlos Marighella, uma das mais significativas lideranças do PCB, resistiu à ordem de prisão em um cinema no bairro da Tijuca, na cidade do Rio de Janeiro. Baleado no peito, afirmou:

Os agentes do DOPS [Departamento de Ordem Política e Social] dispararam um tiro contra o meu peito para me matar, a arma é da polícia, e isto é testemunhado pela bala que foi extraída de meu corpo pelo Dr. Acioly Maia, médico-cirurgião do Hospital da Penitenciária Professor Lemos de Brito. (Marighella, 1994: 13)

Preso, Marighella somente sairia da prisão após decisão judicial em 1965. Tal fato ainda não era uma exceção. A autonomia do judiciário e certas limitações operacionais ao DOPS reduziram o impacto da violência do Estado junto aos cidadãos.

No campo, em especial, a repressão impôs o terror e o governo empregou violência desmedida para conter a luta de classes e atender às demandas requeridas pelos proprietários rurais (Vieira, 2008: 199). Num movimento paradoxal, a repressão se concentrava num marco mínimo de controle junto ao poder central que buscava se apresentar como um instrumento normatizador democrático. Para isso, a continuidade do calendário eleitoral se apresentou como central.

Nesse contexto, as eleições para governadores estaduais em 1965 foram emblemáticas. O então pré-candidato às eleições presidenciais de 1966, Juscelino Kubitschek, se apresentou como um candidato forte ao ver dois aliados serem eleitos em dois importantes estados da União: Israel Pinheiro em Minas Gerais e Francisco Negrão de Lima na Guanabara. ${ }^{2}$ Os candidatos apoiados pelo governo de Castelo Branco saíram derrotados, um claro sinal dos limites de apoio ao governo militar.

A resposta do governo autoritário foi a edição do Ato Institucional n. ${ }^{\circ} 2$ (AI-2), que iniciava um gradual fechamento das parcas liberdades civis. O AI-2 permitiu o aumento do número de ministros no Supremo Tribunal Federal (STF), que passou de 11 para 16 membros, indicados pelo próprio governo, garantindo-lhe maioria na corte. Além disso, ocorreu o reordenamento do campo político ao extinguirem-se os partidos então vigentes (criando assim um bipartidarismo) e definiu-se que as eleições presidenciais de 1966 seriam indiretas, isto é, seriam travadas no Congresso Nacional e não mais por meio de voto direto.

${ }^{2}$ Guanabara passou a designar até 1975 uma nova entidade federativa que correspondia à cidade do Rio de Janeiro, uma vez que esta deixou de ser Distrito Federal e capital da República após a fundação de Brasília em 21 de abril de 1960. 
O AI-2 também permitiu a cassação dos mandatos de parlamentares, como fica claro na leitura do artigo 15 do ato:

Art. 15 - No interesse de preservar e consolidar a Revolução, o Presidente da República, ouvido o Conselho de Segurança Nacional, e sem as limitações previstas na Constituição, poderá suspender os direitos políticos de quaisquer cidadãos pelo prazo de 10 (dez) anos e cassar mandatos legislativos federais, estaduais e municipais. Parágrafo único - Aos membros dos Legislativos federal, estaduais e municipais, que tiverem seus mandatos cassados não serão dados substitutos, determinando-se o quórum parlamentar em função dos lugares efetivamente preenchidos. ${ }^{3}$

A medida sinalizava o efetivo descompromisso do novo regime com a questão democrática e acentuava o embate tênue nas hostes do governo entre uma corrente linha-dura - caracterizada pela defesa da aplicação de uma "guerra suja" visando a contenção definitiva da ameaça subversiva ao país (cf. Vieira et al., 2000: 682) - e uma corrente mais pragmática.

Em 1966, foi editado o Ato Institucional n. ${ }^{\circ} 3$, cuja finalidade era completar a reestruturação política ao transformar eleições para governadores em indiretas, votadas pelas assembleias estaduais. Para o governo militar, esse novo ato consolidou o processo de pacificação e instauração de uma ordem interna favorável aos interesses econômicos externos. O próprio texto do ato assinalava que:

CONSIDERANDO a necessidade de preservar a tranquilidade e a harmonia política e social do País;

CONSIDERANDO que a edição do Ato Institucional n ${ }^{\circ} 2$ estabeleceu eleições indiretas para Presidente e Vice-Presidente da República;

CONSIDERANDO que é imprescindível se estenda à eleição dos Governadores e Vice-Governo de Estado o processo instituído para a eleição do Presidente e do Vice-Presidente da República;

CONSIDERANDO que a instituição do processo de eleições indiretas recomenda a revisão dos prazos de inelegibilidade;

CONSIDERANDO, mais, que é conveniente à segurança nacional alterar-se o processo de escolha dos Prefeitos dos Municípios das Capitais de Estado;

CONSIDERANDO, por fim, que cumpre fixar-se data para as eleições a se realizarem no corrente ano. ${ }^{4}$

\footnotetext{
3 Ato Institucional n. ${ }^{\circ}$ 2, de 27 de outubro de 1965. Presidência da República, Brasília. Consultado a 12.04.2019, em http://www.planalto.gov.br/ccivil_03/AIT/ait-02-65.htm.

${ }^{4}$ Ato Institucional n. 3 de 5 de fevereiro de 1966. Presidência da República, Brasília. Consultado a 05.05.2019, em http://www.planalto.gov.br/ccivil_03/AIT/ait-03-66.htm.
} 
As eleições gerais - isto é, para a presidência da República, o Congresso Nacional e os governadores de estado - foram realizadas em 15 de novembro de 1966, consagrando expressiva vitória do partido governista, a Aliança Renovadora Nacional (ARENA). Também saiu vitorioso o marechal Costa e Silva, candidato indicado pelo alto-comando das Forças Armadas para suceder ao marechal Castelo Branco.

\section{1968: a luta pela democracia nas ruas. Repressão, Al-5 e os anos de chumbo}

Entre 1966 e 1968 um revigoramento da luta contra a ditadura se fez presente. O ex-presidente Juscelino Kubitschek, o líder conservador Carlos Lacerda - cassado pelo governo militar que ajudou a construir ${ }^{5}$ - e o presidente deposto João Goulart se reuniram e organizaram a Frente Ampla. Lacerda assinou um manifesto publicado no Tribuna da Imprensa, que pedia eleições livres e diretas, a reforma partidária e institucional, a retomada de políticas econômicas que visassem o desenvolvimento da economia e a defesa de uma política externa soberana. Em 5 de abril de 1968, o governo editou a portaria n. ${ }^{\circ} 177$, extinguindo a Frente Ampla.

Foi nesse contexto que explodiu a violência policial nas ruas. Em 28 de março de 1968, durante uma manifestação estudantil que defendia a permanência do restaurante popular conhecido como Calabouço, o estudante Edson Luís de Lima Souto acabou morto pela polícia militar da Guanabara. Seu assassinato provocou reação do movimento estudantil:

Aproximadamente 60 mil pessoas participaram do sepultamento de Edson Luís. Seus companheiros se revezavam conduzindo o caixão coberto por uma bandeira nacional. Sua camisa ensanguentada era levada como um estandarte. Apesar de toda a tensão, o cortejo percorreu algumas das principais ruas da cidade sem incidentes. [...] Eram quase oito horas da noite quando o corpo de Edson Luís foi sepultado na gaveta 602, quadra 14, do São João Batista. (Soto e Zappa, 2008: 72)

A violência policial provocou forte reação dos estudantes e de outros setores da sociedade. Ao longo de abril e maio desse ano diversos enfrentamentos entre estudantes e o aparato repressor foram relatados nas cidades brasileiras. No Rio de Janeiro, a Universidade Federal do Rio de Janeiro foi palco, no campus da Praia Vermelha, de batalha campal envolvendo mais de

${ }^{5}$ Carlos Lacerda foi o primeiro governador eleito pela Guanabara e apoiou o golpe de 1964. No entanto viria a criticar o governo de Castelo Branco, afastando-se do mesmo e inclusive articulando a partir de 1966 uma frente de oposição. 
2 mil estudantes reunidos em assembleia, junto ao prédio da então Reitoria. A continuidade dos conflitos provocou reação nas fileiras mais linha-dura entre os militares. Em 26 de junho de 1968, um grande ato envolvendo estudantes, professores, artistas e sociedade civil marcou a oposição contra a ditadura: a Passeata dos 100 mil, no centro do Rio de Janeiro. A imagem de um país controlado, sem conflitos - que era apresentada aos investidores estrangeiros pela ditadura - foi abalada.

Além disso, ampliando o desgaste, em abril e julho de 1968, eclodiram dois movimentos grevistas em áreas industriais estratégicas no projeto de modernização econômica implantado pelo governo: Contagem, em Minas Gerais, e Osasco, em São Paulo. As greves questionavam a política salarial imposta pelo governo, se posicionando contra o arrocho salarial e a corrosão do poder de compra dos trabalhadores.

As greves e a eclosão do movimento estudantil ao confrontarem diretamente a manutenção da ditadura fortaleceram as posições repressoras da linha-dura do regime. Ao longo da segunda metade do ano de 1968, o governo procurou reforçar seu controle sobre as polícias estaduais e conter as agitações estudantis e sindicais. O reitor da Universidade de Brasília pediu a intervenção policial com o argumento que não conseguia garantir a proteção do patrimônio público. Seu pedido foi atendido: em 29 de agosto, sob o pretexto de que buscava cumprir mandado de prisão contra o líder estudantil Honestino Guimarães, policiais civis, militares e tropas do exército invadiram a universidade com brutal violência. Houve bombas de gás, tiros e espancamento generalizado. Registraram-se vários feridos, um estudante perdeu um olho (devido a um tiro no rosto), e Honestino Guimarães foi detido, arrastado e espancado. ${ }^{6}$

Em 12 de outubro do mesmo ano, o congresso da União Nacional dos Estudantes - que se realizava em Ibiúna, São Paulo - foi interrompido por uma operação policial e - as principais lideranças estudantis do país foram presas. Com isso, a ditadura buscava esvaziar a força do movimento estudantil. Entretanto, a peça final estava reservada para dezembro: o governo de Costa e Silva utilizou como pretexto o discurso promovido pelo deputado do Movimento Democrático Brasileiro paulista, Márcio Moreira Alves - considerado ofensivo para com os militares -, para legitimar o efetivo recrudescimento da violência e, no dia 13 de dezembro, apresentou à nação o Ato Institucional n. ${ }^{\circ} 5$ (AI-5).

\footnotetext{
${ }^{6}$ Marques, Marília (2018), "Invasão militar mais violenta à UNB faz 50 anos; Honestino foi 'arrastado, carregado e muito espancado', diz amigo", G1 Globo, 29 de agosto. Consultado a 17.03.2020, em https://g1.globo.com/df/distrito-federal/noticia/2018/08/29/invasao-militar-mais-violenta-a-unb -faz-50-anos-honestino-foi-arrastado-carregado-e-muito-espancado-diz-amigo.ghtml.
} 
[o AI-5] significou a quebra da legalidade imposta pelo próprio regime; dava poderes quase ilimitados ao presidente da República, por exemplo, para legislar por decreto, suspender direitos políticos dos cidadãos, cassar mandatos eletivos, suspender o habeas corpus em crimes contra a segurança nacional, julgar crimes políticos em tribunais militares, demitir ou aposentar juízes e outros funcionários públicos. (Ridenti, 2014: 36)

O AI-5 autorizava o presidente a fechar o Congresso, a cassar mandatos legislativos, a cassar juízes do STF, a decretar estado de sítio por tempo indeterminado, a demitir servidores públicos, a confiscar bens privados e a permitir a intervenção em todos os estados e municípios, entre outros pontos. Alterava ainda o STF reduzindo sua composição, suspendia o direito de habeas corpus para crimes políticos, decretava o fechamento do Congresso Nacional por um ano. Na prática, legitimou o emprego da violência e da arbitrariedade do Estado. Foram permitidas prisões sem autorização judicial; os presos não podiam contatar advogados e familiares, desaparecendo nos porões da repressão, onde muitos morreram após terem sido barbaramente torturados; os corpos das vítimas não foram entregues aos familiares, tornando-se desaparecidos políticos. ${ }^{7}$

O emprego do AI-5 favoreceu a repressão. Sem uma diretiva por parte do alto-comando que limitasse os excessos, o aparelho policial-militar combateu sem piedade a guerrilha urbana, prendendo, torturando, assassinando e fazendo desaparecer corpos vistos como evidência de um crime; no meio rural, a repressão atuou com igual ferocidade diante do movimento organizado pelo PCB nomeadamente na região do Araguaia, então parte integrante de Goiás.

Contra as prisões abusivas e a violência do Estado, setores da oposição que assumiram a luta armada como forma de reação recorreram ao sequestro de representantes dos corpos diplomáticos - dos Estados Unidos, Charles Elbrick; do Japão, Nobuo Okushi; da Suíça, Giovanni Bucher e da Alemanha Ocidental, Ehrenfried von Holleben - para depois trocá-los por presos políticos que seriam então expulsos do Brasil e exilados em outros países. Internamente, ampliou-se a repressão e a violência contra a oposição à ditadura. Em 1974, o governo militar havia derrotado os movimentos de luta armada deixando um saldo de 434 mortos, dos quais 243 se encontram ainda desaparecidos, além de uma ferida até hoje não cicatrizada na sociedade brasileira.

\footnotetext{
${ }_{7}$ Para a oposição de esquerda, a luta política nos espaços oficiais deixava de ser visto como uma opção concreta. Tomava corpo a defesa da luta armada (Gorender, 1987: 153).
} 


\section{A crise da ditadura e a luta pela anistia}

Um dos pilares da sustentação do governo militar junto à sociedade civil foi o período compreendido entre 1968 e 1973, caracterizado por crescimento econômico, expansão das atividades industriais, alargamento do mercado de consumo, aliado ao maior endividamento externo, ampliação das desigualdades sociais, inchaço urbano e favelização.

No entanto, a crise do petróleo de 1973 resultou na redução da oferta de capital externo, implicando em elevação de juros. Além disso, o Brasil se viu obrigado a gastar mais reservas na compra de petróleo junto aos países produtores. A desvalorização cambial resultante da maior valorização do dólar provocou crescente inflação, corroendo o baixo poder de compra dos brasileiros. O quadro afetou a classe média brasileira que

amplamente favorecida no processo de desenvolvimento, através, notadamente, da especulação financeira e imobiliária, sofreu um estrangulamento graças à diminuição do poder aquisitivo, e passou a exigir providências, assim como a classe trabalhadora, insatisfeita com o arrocho salarial e a queda de seu nível de vida. A dívida externa nacional, cuja parte expressiva do capital havia sido investida em obras faraônicas que correspondessem ao crescimento econômico trazido pelo "milagre", também elevou-se consideravelmente, comprometendo os incentivos econômicos. (Ciambarella, 2009: 3)

A crise econômica e seus reflexos sociais se apresentavam como um risco de novos focos de tensões, após a derrocada da resistência armada. A possibilidade de uma retomada da luta nas ruas incomodava a cúpula militar. Por outro lado, internamente, acentuou-se a divisão entre a linha dura e a ala mais pragmática dos militares. O presidente eleito em 1974, o general Ernesto Geisel, representando a ala mais pragmática dos militares, iniciou um projeto político de restauração controlada da democracia, a chamada "abertura lenta, gradual e segura". Com avanços e recuos, tentativas de retomada do controle político por parte da linha dura, Geisel iniciou a abertura e impôs-lhe duro revés ao extinguir o AI-5 em 13 de outubro de 1978 (embora a extinção somente entrasse em vigor em 1 de janeiro de 1979).

O fim do AI-5 e a eleição do general Figueiredo para a presidência da República renovaram as expectativas de um arranjo político para o fim da ditadura. Também permitiram nova retomada de demandas da sociedade civil em favor de maior liberdade. Entre as muitas demandas, tomou forma a defesa dos presos e exilados políticos.

Em 1978, foi fundado no Rio de Janeiro o Comitê Brasileiro da Anistia (CBA), fruto dos debates organizados, desde 1975, pelo Movimento 
Feminino pela Anistia (MFPA). Rapidamente o MFPA criou núcleos em todo o Brasil e divulgou o "Manifesto da Mulher Brasileira" que defendia, entre outros pontos, a anistia ampla, geral e irrestrita. O CBA repetiu a estratégia do MFPA e prontamente novos comitês foram criados em todo o país.

O CBA, conforme Mezarobba (2009) e Souza (2011), buscava o retorno das liberdades democráticas e a defesa dos direitos humanos, o fim da tortura, uma anistia que permitisse a libertação imediata de todos os presos políticos, o retorno de todos os exilados (incluídos os banidos) e perseguidos políticos (inclusive os auto exilados, que saíram do pais para escapar da repressão política), enfim, de todos os que foram atingidos pela lei penal contida na Lei de Segurança Nacional - Decreto-Lei de n. ${ }^{\circ} 898 / 69$, bem como sua revogação e esclarecimento dos casos de desaparecimentos. (Okabayashi e Seixas, 2016: 144)

A expansão dos comitês ampliou a capacidade de mobilização da sociedade em defesa da anistia. Por outro lado, setores significativos do exército, não somente da linha dura, se mostravam contrários a qualquer concessão aos presos políticos e ao retorno dos exilados. Foi nesse contexto que, em 1979, assumiu a presidência o general João Batista Figueiredo. Desde sua posse, Figueiredo se assumiu como um continuador da abertura política. A pressão da sociedade acerca do tema levou o governo a acenar de forma concreta com a possibilidade de apresentar um projeto de lei tratando da anistia.

Nesse contexto, o governo procurava um meio termo entre a defesa da anistia ampla, geral e irrestrita e a garantia de que os militares torturadores não sofreriam punições quando do retorno da democracia. Essa solução de compromisso pautou os debates dentro do governo.

Em 28 de agosto de 1979, o governo viu o Congresso Nacional aprovar a Lei 6.683, que concedia anistia. Em seu artigo primeiro, a lei assinalava:

O PRESIDENTE DA REPÚBLICA: Faço saber que o Congresso Nacional decreta e eu sanciono a seguinte Lei:

Art. $1 .^{\circ}$ É concedida anistia a todos quantos, no período compreendido entre 02 de setembro de 1961 e 15 de agosto de 1979, cometeram crimes políticos ou conexo com estes, crimes eleitorais, aos que tiveram seus direitos políticos suspensos e aos servidores da Administração Direta e Indireta, de fundações vinculadas ao poder público, aos Servidores dos Poderes Legislativo e Judiciário, aos Militares e aos dirigentes e representantes sindicais, punidos com fundamento em Atos Institucionais e Complementares (vetado).

$\$ 1 .^{\circ}$ - Consideram-se conexos, para efeito deste artigo, os crimes de qualquer natureza relacionados com crimes políticos ou praticados por motivação política. 
$\$ 2 .^{\circ}$ - Excetuam-se dos benefícios da anistia os que foram condenados pela prática de crimes de terrorismo, assalto, sequestro e atentado pessoal.

$\$ 3 .^{\circ}-$ Terá direito à reversão ao Serviço Público a esposa do militar demitido por Ato Institucional, que foi obrigada a pedir exoneração do respectivo cargo, para poder habilitar-se ao montepio militar, obedecidas as exigências do art. $3^{\circ} .8$

No entanto, duas polêmicas se levantavam: 1) através do 1. ${ }^{\circ}$ parágrafo da lei de anistia relativo aos chamados crimes conexos, anistiava-se os militares envolvidos com a repressão, a violência, os assassinatos e desaparecimentos de brasileiros nos anos de chumbo; ${ }^{9} 2$ ) a redação da lei excluía os envolvidos diretamente na luta armada.

Os não contemplados pela anistia se utilizaram de um recurso jurídico, isto é, entraram na justiça com pedidos de revisão e redução das penas, o que permitiu a libertação dos presos e o retorno dos exilados. O processo jurídico para garantir a liberdade de todos e o pleno retorno dos exilados somente foi concluído em 1981.

Por outro lado, a impunidade dos militares provocou uma amnésia coletiva, com a sociedade brasileira abrindo mão de exigir justiça e esclarecimentos acerca dos anos de chumbo.

Três pontos centrais da luta dos CBAs não foram contemplados pela lei: (i) o reconhecimento das mortes e dos desaparecimentos; (ii) a responsabilização dos agentes do Estado pela tortura; e (iii) a não reciprocidade. Estas metas só seriam alcançadas, se a lei rompesse com a dimensão do esquecimento, trazendo à tona as atrocidades cometidas durante a Ditadura. A anistia, assim, teria um sentido de anamneses, de reminiscência necessária à consecução da justiça como resgate da memória e direito à verdade, diferentemente da concepção que embasou o projeto governamental: a de anistia como amnésia. (Rodeghero, 2009: 138)

Essa amnésia resultou em tragédia, na medida em que a sociedade brasileira não enfrentou o passado da ditadura, minimizando assim a violência do governo, para além de reduzir a luta por justiça e informação a uma simples questão de revanchismo. Diante desse hiato, foi criada em 2011 a Comissão Nacional da Verdade (CNV), que buscava reconciliar o país

\footnotetext{
${ }^{8}$ Lei n. ${ }^{\circ} 6.683$ de 28 de agosto de 1979. Presidência da República, Brasília. Consultado a 14.05.2019, em http://www.planalto.gov.br/ccivil_03/leis/L6683.htm.

9 Denomina-se "anos de chumbo" o período entre 1968 e 1974, caracterizado pelo maior emprego da violência do Estado contra a oposição, pelas torturas, assassinatos e desaparecimentos dos corpos dos presos políticos.
} 
com seu passado e desvelar o que ainda se encontra encoberto nos porões das Forças Armadas brasileiras.

\section{Justiça de transição: o método da comissão da verdade na América Latina}

Memória, reparação e justiça são temas fundamentais para a reconciliação política em uma sociedade que deseje superar os traumas causados pela violência política. Para tal, é necessário a adoção de métodos e formas de justiça transicional, ou seja, "responder a sistemáticas e amplas violações aos direitos humanos [...] e com isso [...] reconhecer o direito das vítimas, promover a paz, facilitar a reconciliação e garantir o fortalecimento da democracia [...]" (Pinto, 2006: 129), apoiando-se em cinco pilares: verdade, memória, justiça, reparação e implementação de reformas institucionais (CEV-Rio, 2015: 36).

Em contextos de transição, segundo Garretón (2006: 70), os governos democráticos se vêm diante de três propostas desafiadoras: 1) a busca pela verdade máxima, proposta radical de se reconstituir a situação anterior às violações de direitos humanos; 2) a difusão de informação sobre as violações bem como o julgamento e punição dos responsáveis; 3 ) a reparação institucional e simbólica às vítimas em meio à demanda pela conquista e consolidação do regime democrático. Considerando a impossibilidade de se implementar a primeira proposta, resta a adoção da segunda e da terceira a fim de se possibilitar a reconciliação social.

Três modelos de justiça transicional foram identificados em diferentes países, de forma a dar conta dos bloqueios à reconciliação social. O primeiro modelo se refere ao aparato legal, quando são estabelecidas normas de anistia geral e leis de purificação; o segundo modelo trata dos tribunais responsáveis em analisar e julgar os casos de violações de direitos; e o terceiro se refere às práticas como a criação de comissões de inquérito ou de verdade e reconciliação (Pinto, 2006: 48, 61).

O terceiro modelo - com a criação de comissões da verdade - foi adotado em diferentes contextos de transição democrática na América Latina. Resultou de acordos de paz após guerra civil (como nos casos de El Salvador e Guatemala) ou de democratização negociada (como na Bolívia, Chile, Argentina e Uruguai) e teve por objetivo afastar a amnésia política e social sobre as violações de direitos humanos. No entanto, o modelo enfrentou e ainda enfrenta obstáculos. Garretón (2006: 72-73) os classificou como enclaves autoritários à transição democrática, correspondendo à coexistência de normas democráticas com a legislação autoritária (legado institucional); à oposição manifestada por diferentes atores políticos, organizações e setores sociais e à permanência de mentalidades, atitudes e valores antidemocráticos. 
Assim, a primeira comissão da verdade na América Latina, a Comissão Nacional de Inquérito sobre Desaparecimentos da Bolívia, criada em 1982, sob o governo de transição de Hernán Zuazo, teve pouco apoio político e financeiro para investigar abusos cometidos entre 1967 a 1980. Após três anos de trabalho, seus integrantes se dispersaram sem publicar um relatório final, deixando pendente a investigação sobre ossadas de desaparecidos que foram encontradas (Pinto, 2006: 69).

$\mathrm{Na}$ Argentina, a falta de poder coercitivo e a determinação legal para que o poder judiciário apurasse as responsabilidades dos acusados de abusos no período entre 1970 e 1980 foram apontados como empecilhos aos objetivos da Comissão Nacional para Investigação sobre o Desaparecimento de Pessoas, criada em 1983. Contando com a contribuição de sobreviventes, familiares e entidades nacionais e internacionais, a Comissão publicou um relatório final intitulado "Nunca Más: Informe de la Comisión Nacional sobre la Desaparición de Personas”, porém, o governo de transição de Raúl Alfonsín sofreu forte pressão da área militar, o que impediu o julgamento dos acusados naquela ocasião (ibidem: 50-69).

No mesmo sentido, com poderes limitados e com um prazo curto para realização dos seus trabalhos, foi criada em 1985 no Uruguai a Comissão de Investigação da Situação de Pessoas Desaparecidas e suas Causas, num contexto de transição negociada (ibidem: 69). Seu relatório final obteve pouca divulgação e, embora evidenciado o envolvimento das forças de segurança nos casos de violação de direitos, por falta de atribuição da Comissão, não foram investigados relatos de prisões ilegais e tortura.

No Chile, em 1990, no primeiro ano do governo democrático do presidente Patrício Aylwin, foi criada a Comissão Nacional da Verdade e Reconciliação, também conhecida como Comissão Rettig, responsável por investigar violações que ocorreram nos 17 anos de governo militar. Em seu relatório final, o colegiado apresentou 27200 casos de abusos, sem identificar os autores dos mesmos, mas ainda que os identificasse, uma lei de anistia vigente à época impedia que fossem julgados (Ferreira e Rebouças, 2019: 40).

Uma singularidade deve ser destacada no caso da Comissão da Verdade para El Salvador, criada em 1991: devido ao forte contexto de polarização, seus integrantes e funcionários eram todos estrangeiros. Fruto do acordo de paz entre o governo salvadorenho e a Frente de Libertação Nacional Farabundo Martí - que contou com a mediação da Organização das Nações Unidas (ONU) - o colegiado de investigação foi formado por pessoas indicadas pelo secretário-geral da ONU a fim de conferir-lhe imparcialidade. Após publicar seu relatório final, a Comissão foi acusada de exceder seus poderes, desagradando tanto ao governo quanto aos setores militares. Como 
consequência foi promulgada uma lei de anistia geral impedindo o julgamento dos acusados e a adoção das recomendações feitas pela Comissão (Pinto, 2006: 63).

$\mathrm{Na}$ Guatemala, seguindo o exemplo de El Salvador, a ONU mediou o acordo de paz firmado pelo governo com o movimento guerrilheiro União Revolucionária Nacional Guatemalteca. A partir desse acordo foi criada em 1994 a Comissão para o Reconhecimento Histórico da Verdade que, todavia, somente foi instalada em 1997. A Comissão tinha poucos poderes, pois não podia identificar ou acusar os envolvidos nas violações de direitos. Consta em seu relatório final, publicado em 1999, 23671 casos de execuções sumárias e 6159 casos de desaparecimentos forçados, estimando a existência de cerca de 200 mil violações de direitos humanos. Sem poder de julgamento ou de reparação, a Comissão limitou-se às recomendações preventivas e de reparação, com pouca ou nenhuma eficácia para responsabilização dos infratores (FitzGerald, 2010).

\subsection{Percalços da justiça transicional no Brasil: a Comissão Nacional da Verdade}

Analisamos doravante os dois métodos de justiça transicional implementados no contexto do Brasil: as leis de anistia e a comissão da verdade. Quanto ao primeiro método, cabe observar que - desde a fundação da República brasileira em 1889 até 1979 - foram editadas 48 legislações de anistia (Machado apud Cunha, 2010: 15), norteadas pela conciliação. Mas, no caso da anistia de 1979, isso significou a impossibilidade de responsabilização dos transgressores, que os familiares dos desaparecidos políticos e/ou dos mortos pretendiam levar a cabo. A legislação refletiria, assim, a mentalidade conservadora da sociedade brasileira (Cunha, 2010: 35), sendo um dos obstáculos ao processo de transição democrática.

Quando comparado com outros países da América Latina, chama a atenção o lapso temporal entre a promulgação da Carta Constitucional Democrática de 1988 e a instalação da CNV, em 2012. Esse lapso somente pode ser explicado ao examinarmos alguns dos aspectos que caracterizam um processo de redemocratização, em que a liberalização política coexistiu (e ainda coexiste) com parte do arcabouço institucional do período autoritário. De acordo com Acuña e Smulovitz (2006: 50-51), as Forças Armadas estabeleceram os seguintes objetivos no processo de transição brasileiro:

(1) o pessoal militar não deveria ser condenado por crimes políticos (isto é, tortura, sequestro e assassinato); (2) os oficiais demitidos por razões políticas não poderiam 
ser reincorporados; (3) o aparato repressivo deveria ser mantido, e Figueiredo ${ }^{[10]}$ nomearia novos chefes de segurança e inteligência que, por sua vez manteriam suas funções sob um governo civil; (4) as Forças Armadas designariam os ministros do gabinete militar (um para cada uma das três armas, um para a Inteligência, outro para a Casa Militar e um sexto para comandante-em-chefe); (5) a Constituição de 1967, com suas emendas de 1969, seria conservada até que uma nova Constituição fosse aprovada; (6) o grupo encarregado de fazer a revisão da Constituição não deveria ser escolhido por eleições diretas mas, ao contrário, deveria constituir-se dos membros incumbidos do Congresso; e (7) a reforma institucional ficaria restrita a questões que não afetassem a "segurança nacional".

Com a garantia da maioria daqueles objetivos, os riscos de interrupção do processo de transição democrático foram afastados e, em 1985, dois civis que tinham bom relacionamento com as Forças Armadas, foram eleitos indiretamente para ocupar a presidência e a vice-presidência do Brasil, respectivamente Tancredo Neves ${ }^{11}$ e José Sarney, demarcando o fim do regime militar (Acuña e Smulovitz, 2006: 51).

Nesse contexto político foi preciso que, nos anos seguintes, familiares dos mortos e dos desaparecidos políticos e militantes dos direitos humanos continuassem mobilizados a fim de manter a visibilidade das suas demandas, pressionando o poder à adoção de políticas públicas de investigação, responsabilização e reparação nos casos de violação de direitos relacionados com o período da ditadura militar.

O Grupo Tortura Nunca Mais, no Rio de Janeiro, e o projeto Brasil: Nunca Mais, em São Paulo - que iniciou suas atividades em 1979 - são exemplos dessa mobilização contínua. Este último publicou, em 1985, o livro Um relato para a bistória. Brasil: Nunca Mais, apresentando os resultados do projeto que reuniu de forma sistematizada documentos oficiais, testemunhos e reportagens da imprensa nacional sobre denúncias dos locais e formas de tortura com a identificação de algumas das vítimas e dos torturadores do regime de $1964 .{ }^{12}$ Essa mobilização contribuiu para que, em 1990, fosse localizada a Vala de Perus, no cemitério Dom Bosco em São Paulo - na qual mais de mil ossadas foram encontradas ${ }^{13}$ e para a localização, no Rio de Janeiro, de 14 ossadas enterradas em uma vala

\footnotetext{
${ }_{10}$ General João Baptista de Figueiredo, presidente do Brasil entre 1979 e 1985.

${ }^{11}$ Falecido antes que tomasse posse no cargo. José Sarney assumiu então a Presidência, governando o país de 1985 a 1990.

${ }_{12}$ Disponível em http://bnmdigital.mpf.mp.br/pt-br/. Consultado a 01.03.2020.

13 Piva, Juliana Dal (2018), “Após 27 anos, Comissão de Mortos e Desaparecidos identifica ossada da Vala de Perus em SP", O Globo, 20 de fevereiro. Consultado a 18.06.2019, em https://oglobo. globo.com/brasil/apos-27-anos-comissao-de-mortos-desaparecidos-identifica-ossada-da-vala-deperus-em-sp-22414116.
} 
clandestina no Cemitério de Ricardo de Albuquerque. ${ }^{14}$

No entanto, essas ações não evitaram que arquivos desaparecessem, documentos fossem destruídos e que trabalhos de identificação das vítimas fossem interrompidos. Em uma tentativa de assegurar que uma política pública de Estado fosse implementada, familiares das vítimas e militantes dos direitos humanos conseguiram que os dois principais candidatos ao pleito presidencial de 1994 se comprometessem em adotar medidas de apuração sobre as mortes e desaparecidos políticos.

Uma vez eleito, o presidente Fernando Henrique Cardoso articulou a aprovação da Lei n. ${ }^{\circ}$ 9.140/95, junto ao Congresso Nacional que criou a Comissão Especial sobre Mortos e Desaparecidos Políticos (CEMDP). ${ }^{15}$ Esse ato normativo foi considerado inaugural do processo de reconhecimento oficial das violações praticadas por agentes do Estado brasileiro. A lei admitia a indenização pecuniária aos familiares e identificou nominalmente 136 pessoas que foram reconhecidas como sendo desaparecidos políticos.

Persistindo em seus objetivos, familiares das vítimas e militantes de direitos humanos, insatisfeitos com a demora do poder judiciário brasileiro em julgar uma ação iniciada em 1995 que tratava dos desaparecidos na Guerrilha do Araguaia, ${ }^{16}$ denunciaram o caso à Corte Interamericana de Direitos Humanos (CDIH) da Organização dos Estados Americanos. Em 2010, a Corte declarou a responsabilidade do Estado brasileiro pelos desaparecimentos forçados da Guerrilha, assinalando a inadequação da Lei de Anistia brasileira frente à Convenção Americana sobre Direitos Humanos. ${ }^{17} \mathrm{Na}$ sentença estão assinalados diversos dos deveres a serem cumpridos pelo Estado brasileiro, como o de investigar os fatos; responsabilizar os autores das violações; determinar o paradeiro dos desaparecidos; disponibilizar assistência médica e psicológica aos sobreviventes assim como difundir os fatos. ${ }^{18}$

Outros êxitos foram obtidos mediante duas alterações legais. Através da alteração da Lei 9.140/95 pelo Congresso Nacional modificou-se o período estabelecido para o reconhecimento de pessoas dadas como mortas e

${ }_{14}$ Grupo Tortura Nunca Mais/RJ (2019), "Memorial Ricardo de Albuquerque", 27 de abril. Consultado a 18.06.2019, em http://www.torturanuncamais-rj.org.br/memorial-ricardo-de-albuquerque/.

${ }^{15}$ Lei n. ${ }^{\circ}$ 9.140, de 4 de dezembro de 1995. Presidência da República, Brasília. Consultado a 14.06.2019, em http://www.planalto.gov.br/ccivil_03/LEIS/L9140.htm.

${ }_{16}$ Movimento de luta armada (guerrilheiro) que ocorreu na região do Araguaia (divisa entre os estados de Tocantins e Pará), entre os anos de 1972 e 1975.

${ }_{17}$ Disponível em http://www.corteidh.or.cr/docs/casos/articulos/seriec_219_por.pdf. Consultado a 01.03 .2020 .

${ }^{18}$ Ver nota de rodapé anterior. 
desaparecidas, que passou de 2 de setembro de 1961 a 15 de agosto de 1979 para 2 de setembro de 1961 a 5 de outubro de 1988. A segunda alteração ocorreu em 2004, com a ampliação da competência da CEMDP para investigar casos de mortes em decorrência da repressão policial em manifestações públicas ou em conflitos armados com agentes do poder público. ${ }^{19}$

Somando as pautas defendidas pelos familiares das vítimas e militantes dos direitos humanos, à aprovação, em 2009, do Programa Nacional de Direitos Humanos 3 e à sentença condenatória de 2010 da CIDH, nos deparamos com o contexto em que, em 2010, o presidente da República Luiz Inácio Lula da Silva expediu um ato presidencial instituindo um grupo de trabalho responsável por elaborar o anteprojeto de lei de criação da CNV, que tramitou e foi convertido na Lei 12.528 de 2011.

Em maio de 2012, os membros da CNV foram empossados pela presidente Dilma Rousseff (ela própria uma das vítimas do regime de 1964) em uma grande solenidade no Palácio do Planalto, que contou com a presença dos quatro ex-presidentes da transição democrática - José Sarney, Fernando Collor de Mello, Fernando Henrique Cardoso e Luiz Inácio Lula da Silva.

A CNV recebeu apoio de diferentes setores da sociedade, como da Ordem dos Advogados do Brasil (Conselho Federal), de magistrados e profissionais liberais. Mas por outro lado, ativistas dos direitos humanos criticaram a ausência de poder punitivo da Comissão - que significava que justiça não seria feita - assim como a extensão do período a ser investigado, entre setembro de 1946 e outubro de 1988, por um colegiado apenas composto por oito pessoas (Sanson, 2012).

Em mais de uma ocasião, segmentos ligados às Forças Armadas manifestaram sua contrariedade diante de qualquer iniciativa que significasse a responsabilização civil ou criminal de agentes acusados de cometer violações de direitos humanos. ${ }^{20}$ Dessa forma, em relação à instalação da CNV, foi publicado e depois retirado do sítio eletrônico do Clube Militar um manifesto intitulado "Alerta à Nação - Eles que venham, aqui não passarão", postulando que a aprovação da CNV foi "um ato inconsequente, de revanchismo explícito e de afronta à Lei da Anistia com o beneplácito, inaceitável, do atual governo". ${ }^{21}$

\footnotetext{
${ }^{19}$ Lei n. $^{\circ}$ 9.140, de 4 de dezembro de 1995. Presidência da República, Brasília. Consultado a 14.06.2019, em http://www.planalto.gov.br/ccivil_03/LEIS/L9140.htm.

${ }^{20}$ Agência Estado (2008), "Punição por crimes na ditadura revolta militares", Gazeta do Povo, 31 de julho. Consultado a 18.06.2019, em https://www.gazetadopovo.com.br/vida-publica/ punicao-por-crimes-na-ditadura-revolta-militares-b3 pej2igyzy530txlc8ap1utq/.

${ }^{21}$ Agência O Globo (2012), "Militares reagem e aumenta adesão a manifesto contra o governo", Gazeta do Povo, 2 de março. Consultado a 18.06.2019, emhttps://www.gazetadopovo.com.br/vida-publica/ militares-reagem-e-aumenta-adesao-a-manifesto-contra-o-governo-6ze5d0ksgfffmysfx62t7myj2/.
} 
A CNV (Brasil, 2014a: 42) tinha os seguintes objetivos:

I - esclarecer os fatos e as circunstâncias dos casos de graves violações de direitos humanos mencionados no caput do artigo 1. ${ }^{\circ}$;

II - promover o esclarecimento circunstanciado dos casos de torturas, mortes, desaparecimentos forçados, ocultação de cadáveres e sua autoria, ainda que ocorridos no exterior;

III - identificar e tornar públicos as estruturas, os locais, as instituições e as circunstâncias relacionados à prática de violações de direitos humanos mencionadas no caput do artigo $1 .^{\circ}$ e suas eventuais ramificações nos diversos aparelhos estatais e na sociedade;

IV - encaminhar aos órgãos públicos competentes toda e qualquer informação que possa auxiliar na localização e identificação de corpos e restos mortais de desaparecidos políticos, nos termos do artigo $1 .^{\circ}$ da Lei n. ${ }^{\circ} 9.140$, de 4 de dezembro de 1995;

V - colaborar com todas as instâncias do poder público para apuração de violação de direitos humanos [...];

VI - recomendar a adoção de medidas e políticas públicas para prevenir violação de direitos humanos, assegurar sua não repetição e promover a efetiva reconciliação nacional;

VII - promover, com base nos informes obtidos, a reconstrução histórica dos casos de graves violações de direitos humanos, bem como colaborar para que seja prestada assistência às vítimas de tais violações.

A estrutura administrativa da CNV compreendia três subcomissões: pesquisa, geração e sistematização de informações; relações com a sociedade civil e instituições; subcomissão de comunicação externa. As subcomissões desenvolviam investigações descentralizadas com equipes de pesquisa autônomas, organizadas em 13 grupos de trabalhos com as seguintes temáticas: ditadura e gênero; Araguaia; contextualização, fundamentos e razões do golpe civil-militar de 1964; ditadura e sistema de justiça; ditadura e repressão aos trabalhadores e ao movimento sindical; estrutura de repressão; mortos e desaparecidos políticos; graves violações de direitos humanos no campo ou contra indígenas; Operação Condor; papel das igrejas durante a ditadura; perseguições a militares; violações de direitos humanos de brasileiros no exterior e de estrangeiros no Brasil; o Estado ditatorial-militar.

Além das subcomissões e dos grupos de trabalho, a CNV contou com uma assessoria de comunicação (divulgação de atividades e manifestações), uma ouvidoria (transparência, prestação de contas e colaborações da 
sociedade) e um núcleo de perícias e diligências (elucidação das circunstâncias das mortes, caracterização dos locais e métodos das violações). Com essa estrutura, a Comissão trabalhou entre 16 de maio de 2012 a 10 de dezembro de 2014, documentando as ocorrências de violações de direitos humanos entre 1946 e 1988 e, de acordo com o relatório final, notadamente do período entre 1964 e 1985 (Brasil, 2014a: 53, 962 ss.).

Em seu relatório final, a CNV fez constar que:

[a] comprovação decorreu da apuração dos fatos que se encontram detalhadamente descritos neste Relatório, nos quais está perfeitamente configurada a prática sistemática de detenções ilegais e arbitrárias e de tortura, assim como o cometimento de execuções, desaparecimentos forçados e ocultação de cadáveres por agentes do Estado brasileiro. Para essa apuração, a CNV valeu-se de elementos consistentes, frutos de sua atividade de pesquisa, bem como de evidências obtidas por órgãos públicos, entidades da sociedade civil e vítimas e seus familiares, que, antes da existência da comissão, se dedicaram a essa busca. (ibidem: 962-963)

A CNV identificou de forma individualizada 191 mortos, 210 desaparecidos e 33 desaparecidos cujos corpos foram localizados, totalizando assim 434 casos (ibidem: 963). Igualmente, o colegiado identificou nominalmente 377 agentes estatais que, por suas ações, carrearam para si a responsabilidade político-institucional; responsabilidade pelo controle e gestão da estrutura e procedimentos; responsabilidade pela autoria direta de condutas de violações, que segundo a Comissão configuram crimes contra a humanidade (ibidem: 844-931). Ainda, de acordo com as investigações realizadas pela CNV, o contingente de militares perseguidos chegou aos 6591, entre integrantes da aeronáutica, exército e marinha (Brasil, 2014b: 13).

O relatório continha 29 recomendações, cujo objetivo, segundo a CNV, era:

[...] prevenir graves violações de direitos humanos, assegurar sua não repetição e promover o aprofundamento do Estado democrático de direito, CNV recomenda a adoção de um conjunto de dezessete medidas institucionais e de oito iniciativas de reformulação normativa, de âmbito constitucional ou legal, além de quatro medidas de seguimento das ações e recomendações da CNV. (Brasil, 2014a: 964)

Entre elas destacamos: 1) medidas institucionais: reformulação dos concursos de ingresso e dos processos de avaliação contínua nas Forças Armadas e na área de segurança pública, de modo a valorizar o conhecimento sobre os preceitos inerentes à democracia e aos direitos humanos; 
2) medidas para reformas constitucionais e legais: o aperfeiçoamento da legislação brasileira para tipificação das figuras penais correspondentes aos crimes contra a humanidade e ao crime de desaparecimento forçado; 3) medidas de seguimento das ações e recomendações da CNV: estabelecimento de órgão permanente com atribuição de dar seguimento às ações e recomendações da CNV.

O relatório final é o registro de todas as atividades da Comissão e a sua publicação, em três volumes, foi disponibilizada por meio impresso e virtual. Além desse, outros documentos, vídeos, áudios e fotografias estão permanentemente acessíveis no sítio da CNV. ${ }^{22}$ Entre esses materiais se encontram 75 audiências públicas realizadas em diversos estados da Federação, depoimentos colhidos em parceria com as Comissões Regionais, seminários, homenagens, laudos periciais, relatórios de pesquisa e requisições encaminhadas para apuração de violações de direitos.

Criticado por diferentes segmentos da sociedade, os resultados apresentados pela CNV evidenciaram a ausência de uma reconciliação nacional em torno das violações de direitos humanos nos períodos autoritários. De um lado, segmentos ligados aos militares, contestaram algumas recomendações como a de desmilitarizar as polícias estaduais ${ }^{23}$ e atribuíram os resultados apresentados ao ódio e ao desejo de vingança. ${ }^{24}$ Militantes dos direitos humanos e sobreviventes do regime ditatorial, por seu turno, classificaram o relatório como frustrante e superficial e acusaram a Comissão de ter suavizado "a narrativa de abusos cometidos por militares, substituindo o termo 'tortura' pela usual terminologia 'graves violações de direitos humanos' [...]” (Neto, 2018: 98). A própria Comissão assinalou em seu relatório que os resultados foram aqueles possíveis "em função do trabalho realizado, apesar dos obstáculos encontrados na investigação, em especial a falta de acesso à documentação produzida pelas Forças Armadas, oficialmente dada como destruída" (Brasil, 2014a: 963).

Nesse diapasão, o acesso a outros documentos referentes ao período do regime militar de 1964, liberados pelo governo dos Estados Unidos em 2018, evidenciaram os bloqueios que foram impostos aos trabalhos da CNV. As novas informações contidas nesses documentos contribuíram para que

\footnotetext{
${ }^{22}$ Disponível em http://cnv.memoriasreveladas.gov.br/.

${ }^{23}$ Falcão, Márcio (2018), "Justiça nega pedido de federação de militar contra ato da Comissão da Verdade", JOTA, 11 de junho. Consultado a 18.06.2018, em https://www.jota.info/paywall? redirect_ to=//www.jota.info/justica/justica-nega-pedido-de-federacao-de-militar-contra-ato-da-comissao-verdade11062018.

${ }^{24}$ Quaino, Lilian (2014), "Clube militar publica lista de mortos pelo irracionalismo do terror", G1.Globo, 11 de dezembro. Consultado a 04.11.2019, em http://g1.globo.com/politica/noticia/2014/12/clube-militar-homenageia-brasileiros-mortos-pelo-irracionalismo-do-terror.html.
} 
familiares de mortos e de desaparecidos políticos pleiteassem junto ao STF o reexame da constitucionalidade da Lei da Anistia de 1979, com o intuito de este poder declarar a imprescritibilidade de crimes como o homicídio e a tortura quando cometidos por agentes do Estado. ${ }^{25}$ Também no Congresso Nacional representantes políticos se mobilizaram para que dois projetos de lei que tratavam do mesmo tema voltassem a ser debatidos no Senado e na Câmara ${ }^{26}$ No entanto, não houve avanços para que essa demanda fosse acolhida, seja no reexame pelo STF, seja na aprovação de um dos dois projetos de lei. Por fim, em uma análise feita em 2019, concluiu-se que das 29 recomendações contidas no relatório final da CNV, apenas 5 foram cumpridas, 6 foram parcialmente cumpridas e 18 não foram implementadas. ${ }^{27}$

\section{Conclusão}

Em retrospectiva, verifica-se que, dos cinco pilares da justiça de transição, o Estado brasileiro adotou, em primeiro plano, três deles: políticas públicas reparatórias, de caráter pecuniário-indenizatório; efetivação do direito à verdade; e efetivação do direito à memória - porém, sem a robustez necessária para imprimir mudanças institucionais ou mesmo a justiça demandada por familiares dos mortos e dos desaparecidos políticos. Ao deixar em segundo plano e com reduzida efetividade aqueles dois pilares da justiça de transição, foram mantidas lógicas internalizadas em relação aos valores democráticos nos setores mais conservadores da sociedade brasileira, fortalecendo os opositores do processo de transição que restou incompleto.

Portanto, as políticas públicas reparatórias de caráter pecuniário-indenizatório e os trabalhos realizados para efetivação do direito à verdade e do direito à memória até então implementados se mostraram insuficientes à reconciliação nacional, ante a impossibilidade em responsabilizar os perpetradores das violações de direitos humanos. Com isso, o legado institucional autoritário coexiste com normas democráticas. Esses dois fatores têm sido suficientemente fortes para impedir que o processo de transição democrática se complete no Brasil, situação evidenciada recentemente

\footnotetext{
${ }^{25}$ Baptista, Rodrigo (2018), "Membros da Comissão Nacional da Verdade pedem que STF reveja Lei da Anistia”, Senado Notícias, 24 de maio. Consultado a 18.06.2019, em https://www12.senado.leg.br/ noticias/materias/2018/05/24/membros-da-comissao-nacional-da-verdade-pedem-que-stf-reveja-leida-anistia.

${ }^{26}$ Melo, Karine; Brito, Debora (2018), "Parlamentares querem desengavetar proposta que revisa Lei de Anistia”, Agência Brasil, 14 de maio. Consultado a 07.02.2020, em http://agenciabrasil.ebc.com. br/politica/noticia/2018-05/parlamentares-querem-desengavetar-proposta-que-revisa-lei-de-anistia. ${ }_{27}$ Potter, Hyury (2019), "Quatro anos depois, Brasil ignora maioria das recomendações da Comissão da Verdade”, Aos Fatos, 29 de março. Consultado a 11.06.2019, em https://aosfatos.org/noticias/ quatro-anos-depois-brasil-ignora-maioria-das-recomendacoes-da-comissao-da-verdade/.
} 
quando novos fatos sobre o regime militar de 1964 vieram a público, ${ }^{28}$ fazendo com que integrantes dos movimentos sociais, militantes de direitos humanos e familiares de mortos e desaparecidos políticos continuem mobilizados, reivindicando a memória, a verdade, a reparação, a justiça e mudanças institucionais.

Revisto por Ana Sofia Veloso

\section{Referências bibliográficas}

Acuña, Carlos; Smulovitz, Catalina (2006), "O ajuste das forças armadas à democracia: sucessos, fracassos e ambiguidades no Cone Sul”, in Elizabeth Jelin; Eric Hershberg (orgs.), Construindo a democracia: direitos humanos, cidadania e sociedade na América Latina. São Paulo: EDUSP, 35-69. Tradução de Ana Luiza Pinheiro.

Bobbio, Norberto; Matteucci, Nicola; Pasquino, Gianfranco (1995), Dicionário de politica. Brasília: Universidade de Brasília. Tradução de Carmen C. Varriale, Gaetano Lo Mônaco, João Ferreira, Luís Guerreiro Pinto Cacais e Renzo Dini.

Brasil (2014a), "Comissão Nacional da Verdade", volume 1. Brasília: CNV. Consultado a 18.06.2019, em http://cnv.memoriasreveladas.gov.br/images/pdf/relatorio/ volume_1_digital.pdf.

Brasil (2014b), "Comissão Nacional da Verdade", volume 2. Brasília: CNV. Consultado a 18.06.2019, em http://cnv.memoriasreveladas.gov.br/images/pdf/relatorio/ volume_2_digital.pdf.

CEV-Rio - Comissão da Verdade no Rio (2015), "Comissão da Verdade do Rio Relatório”. Rio de Janeiro: CEV-Rio. Consultado a 18.06.2019, em http://www. memoriasreveladas.gov.br/administrator/components/com_simplefilemanager/ uploads/Rio/CEV-Rio-Relatorio-Final.pdf.

Cunha, Paulo Ribeiro da (2010), "Militares e anistia no Brasil: um dueto desarmônico", in Edson Teles; Vladimir Saflate (orgs.), O que resta da ditadura: a exceção brasileira. São Paulo: Boitempo Editorial, 15-40.

Dreifuss, René Armand (1987), 1964: a conquista do Estado. Ação política, poder e golpe de classe. Petrópolis: Vozes.

Ferreira; Alex Daniel Barreto; Rebouças, Gabriela Maia (2019), "As lutas sociais pela efetivação do direito à verdade e a memória: uma análise a partir das experiências da Argentina, Chile e Brasil”, in Alejandro González-Varas Ibáñez; José Claudio Monteiro de Brito Filho; Luciana Aboim Machado Gonçalvez da Silva;

$\overline{{ }_{28}}$ Borges, Rodolfo (2018), "Documento da CIA sobre execuções 'implode' versão oficial da ditadura", El País, 16 de maio. Consultado a 01.03.2020, em https://brasil.elpais.com/brasil/2018/05/11/politica/1526053261_197839.html. 
Maria Aurea Baroni Cecato; Raymundo Juliano Feitosa (coords.), Efetividade dos direitos humanos, culturas jurídicas e movimentos sociais e direitos do trabalbo e eficácia dos direitos fundamentais no ambiente do trabalbo. Zaragoza: Prensas de la Universidad de Zaragoza/Editora LEFIS, 32-50.

FitzGerald, Garret (2010), "The Truth Comissions of Guatemala. Pluralism and Particularity within the Human Right Paradigm”. Consultado a 05.02.2020, em https://projects.iq.harvard.edu/hdsjournal/book/truth-commissions-guatemala.

Freixo, Adriano; Freitas, Jacqueline Ventapane; Munteal Filho, Oswaldo (orgs.) (2008), Tempo negro, temperatura sufocante. Rio de Janeiro: Contraponto/Ed. PUC Rio.

Garretón, Manuel Antonio (2006), "Os direitos humanos nos processos de democratização”, in Elizabeth Jelin; Eric Hershberg (orgs.), Construindo a democracia: direitos humanos, cidadania e sociedade na América Latina. São Paulo: EDUSP, 71-93. Tradução de Ana Luiza Pinheiro.

Gorender, Jacob (1987), Combate nas trevas. A esquerda brasileira: das ilusões perdidas à luta armada. São Paulo: Ática.

Marighella, Carlos (1994), Por que resisti à prisão. São Paulo: Brasiliense.

Neto, Modesto Cornélio Batista (2018), A democracia no Brasil. Comissão Nacional da Verdade e construção democrática. Desafios e limites da construção democrática. Rio de Janeiro: Editora Gramma [1. a ed.].

Okabayashi, Koji; Seixas, Henrique (2016), “A Lei de Anistia de 1979 e a construção do estado democrático de direito no Brasil”, Universitas, 9(16), 135-162.

Pinto, Simone Martins Rodrigues (2006), "Justiça transicional restaurando o passado e construindo o futuro”, in Clóvis Brigadão; Valérie de Campos Mello (orgs.), Diplomacia cidadã: panorama brasileiro de prevenção de conflitos internacionais. Rio de Janeiro: Editora Gramma/Fundação Konrad Adenauer, 48-76.

Ridenti, Marcelo (2014), “As oposições à ditadura: resistência e integração”, in Daniel Aarão Reis; Marcelo Ridenti; Rodrigo Patto Sá Motta (orgs.), A ditadura que mudou o Brasil. Rio de Janeiro: Zahar, 30-47.

Rodeghero, Carla Simone (2009), “A anistia entre a memória e o esquecimento”, História Unisinos, 13(2), 131-139.

Sanson, Cesar (2012), “Comissão da Verdade: avanços e limites”, Brasil de Fato, 13 de junho. Consultado a 18.06.2019, em https://www.brasildefato.com.br/node/9803/.

Soto, Ernesto; Zappa, Regina (2008), 1968: eles só queriam mudar o mundo. Rio de Janeiro: Zahar.

Vieira, Fernando Antonio da Costa (2008), "Nos idos do AI-5: violência e conflito no campo", in Adriano Freixo; Jacqueline Ventapane Freitas; Oswaldo Munteal Filho (orgs.), Tempo negro, temperatura sufocante. Rio de Janeiro: Contraponto/Ed. PUC Rio, 191-206.

Vieira, Fernando Antonio da Costa; Aquino, Rubin; Agostino, Gilberto; Roedel, Hiran (2000), Sociedade brasileira: uma história através dos movimentos sociais. Da crise do escravismo ao apogeu do neoliberalismo. Rio de Janeiro: Record. 
Artigo recebido a 01.07.2019

Aprovado para publicação a 16.10.2019

Celia Regina do Nascimento de Paula

UCAM - Universidade Candido Mendes I GENTES - Grupo de Estudos sobre Novas

Tendências Sociais

Rua Luiz Leopoldo Fernandes Pinheiro, 517, Centro, Niterói, RJ, CEP: 24016-900,

Estado do Rio de Janeiro, Brasil

Contacto: professoraceliadepaula@gmail.com

ORCID: https://orcid.org/0000-0002-1580-6088

\section{Fernando Antonio da Costa Vieira}

IUPERJ/UCAM - Instituto Universitário de Pesquisas do Rio de Janeiro da Universidade

Candido Mendes

Rua Marquês de São Vicente, 30/1002, CEP: 22451-040, Gávea, Rio de Janeiro, Brasil

Contacto: fernandoacvieira@gmail.com

ORCID: https://orcid.org/0000-0002-5279-7969

\section{The Truth Commission in Brazil: The Struggle for Memory in a Fragile Democracy}

Brazil's National Truth Commission (CNV), established in 2012, presented a report of its actions in 2014. By publishing the report, the CNV was able to identify the agents of the State who violated human rights by presenting reports on the deaths of 434 people, victims of arbitrary actions, including descriptions of torture techniques, executions, illegal arrests, disappearances and hiding victim's bodies. The present work aims to discuss CNV action within the limits that have been imposed - those which heed the Amnesty Law of 1979 - and the axis of the struggle to rescue the missing memory denied to the political desaparecidos. The analysis of documents produced by the CNV, and the reports produced by the media, will be the material used for the production of this article.

Keywords: amnesty; Brazil; dictatorship; memory; political prisoners.

\section{La Commission de la vérité au Brésil: la lutte pour la mémoire dans une démocratie fragile}

Créée au Brésil en 2012, la Commission nationale de la vérité (CNV) a présenté un rapport de ses actions en 2014. En le rendant public, la CNV, en plus de citer nominalement des agents de l'État qui ont violé les droits humains, a fait état de la mort de 434 personnes, victimes d'actes arbitraires et a présenté des descriptions de techniques de torture, d'exécutions, de détentions illégales, de disparitions forcées et de dissimulation de cadavres. Le présent article vise à discuter l'action de la CNV dans les limites qui lui ont été imposées tenir compte de la Loi d'amnistie de 1979 - et de l'axe de la lutte pour le sauvetage de la mémoire niée aux disparus politiques. L'analyse des documents produits par la CNV et les informations véhiculées par les médias seront le matériel utilisé pour la production de cet article.

Mots-clés: amnistie; Brésil; dictature; mémoire; prisonniers politiques. 
